\title{
Numerical Investigation of Forced Convection Heat Transfer on a Circular Finned tube with AL2O3-Water Nano Fluid
}

\author{
Khudheyer, Ahmed F. and Hameed, Raghad A. \\ ${ }^{1}$ Khudheyer, Ahmed F. Alnahrain- university.IRAQ, \\ ${ }^{2}$ Hameed, Raghad A. BSc Mechanical Engineering/ Alnahrain- university.IRAQ
}

\begin{abstract}
This paper presents a three-dimensional numerical analysis to study the laminar forced convection heat transfer and flow characteristics of $\mathrm{AL}_{2} \mathrm{O}_{3}$-water Nano fluid with Solid particles less than $100 \mathrm{~nm}$ through a tube with $1 \mathrm{~m}$ Length and $25 \mathrm{~mm}$ inner diameter and $30 \mathrm{~mm}$ outer diameter contains circular fins with $30 \mathrm{~mm}$ inner diameter and $50 \mathrm{~mm}$ outer diameter with thickness of $2 \mathrm{~mm}$, investigated numerically by using finite volume method, models using ANSYS 14.5 Based on the single-phase approach, The flow of fluid is assumed to be incompressible, steady and laminar with various thermo physical properties according to volume concentration of Nano particles The Navies Stokes equations along with the energy equation have been solved by using SIMPLE algorithm Technique. The effects of different parameters such as nanoparticle volume concentration (1\%,3\% and 5\%), and Reynolds number are varied from $(500-2100)$ for various axial locations of tube with AL2O3-water fluids and the effect of different values of velocity at the tube inlet will be studied during this paper. Where the results showed that the coefficient of heat transfer increases when the concentration of Nano fluid increase.
\end{abstract}

Keywords- forced convection-circular finned tube-AL2O3 Nanofluid - Navier Stokes

\section{Nomenclature}

The following symbols are used generally throughout the text. Others are defined as and when used.

\section{Symbols}

$\mathrm{Cp}$

$\mathrm{K}$

$\mathrm{Nu}$

$\mathrm{P}$

$\operatorname{Re}$

$\mathrm{T}$

$\mathrm{V}$

$\mathrm{X}$

Greek letters

$\alpha$

$\phi$

\section{Meaning}

Units

Specific heat at constant pressure

Thermal conductivity

Nusselt number

Pressure

Reynolds number

Temperature

Velocity vector

Distance along axis

Thermal diffusivity

$\mathrm{m} 2 / \mathrm{s}$

\section{$\mathrm{J} / \mathrm{kg} . \mathrm{K}$}

$\mathrm{W} / \mathrm{m} . \mathrm{K}$

$\mathrm{Pa}$

K

$\mathrm{m} / \mathrm{s}$

$\mathrm{m}$

Volume fraction 


\section{Subscripts}

bf

f

nf

S
Base fluid

Fluid

Nanofluid

Solid of particle

\section{Introduction}

Heat exchangers are usually used devices that transfer heat from one fluid (gas or liquid) to another without those two fluids mixing. Heat transfer enhancement is the process of enhancing the performance of a heat transfer unit. It is used in heating, air conditioning systems in a household, chemical processing, power production in large plants, There are different methods used to increase the heat transfer rate in compact heat exchangers One of these methods is the use of Extended surfaces "finned tube" Achieving higher heat transfer rate by increasing heat transfer area and increasing flow mixing in the boundary layer is the main goal for these methods and The other method is to increase the thermal conductivity of fluid by used Nano fluid. Proposed the use of Nano fluids which are having extremely impressive and attractive thermal properties [1]

This study aims to enhance the heat transfer characteristics for heat exchanger with use of Nano fluid and finned tube.

Zamzamian (2011) [2], studied numerically the effect of forced convective heat transfer of nanofluids of aluminum oxide and copper oxide prepared in ethylene glycol in turbulent flow. They discover vast enhancement in convective heat transfer coefficient of the nanofluids in contrast to the base fluid. Furthermore, their outcomes show that with expanding nanoparticles concentration and nanofluid temperature, the convective heat transfer coefficient of nanofluid will increases.

Naik (2013) [3], analyzed turbulent convective flow of $\mathrm{CuO}$ nanofluids of propylene glycolwater as the base fluid and flow through a circular tube, subjected to a regular and uniform heat flux at the wall. They found that nanofluids containing extra concentrations have proven higher heat transfer coefficient. They compared their numerical results with the experimental data and affordable appropriate agreement is performed.

Sheikholeslami (2014) [4] , observed numerically the impact of natural convection heat transfer in a nano fluid $(\mathrm{CuO})$ crammed enclosure with elliptic internal cylinder. They observed that Nusselt number increments with an increment each of nanoparticles volume fraction, Rayleigh numbers and inclination angle. .Likewise, they found that expanding Rayleigh number prompts a lessening in heat transfer enhancement. For high Rayleigh number the minimum heat transfer enhancement ratio occurs at slanted elliptic cylinder is 90 .

Hsien-Hung and Shuhn-Shyurng(2014)[5], numerically research the convective heat transfer of water-based A12O3 nanofluids flowing through a square cross section duct with a fixed heat flux under laminar flow conditions. They investigated the influences of nanoparticle concentration and Peclet number on the heat transfer attributes of Al2O3-water nanofluids. The nanoparticle diameter is $25 \mathrm{~nm}$ and six particle concentrations $(0.2,0.5,1,1.5,2$, and 2.5 vol. \%) are taken into consideration. They confirmed that the heat transfer coefficients and Nusselt number of A12O3-water nanofluids increment with expansions within the Peclet number and similarly particle volume concentration. The heat transfer coefficient of nanofluids is elevated via $25.5 \%$ at a particle volume concentration of $2.5 \%$ and a Peclet quantity of 7500 as contrasted with that of the base fluid (pure Water). 
Bouhalleba and Abbassi (2016) [6], analyzed numerically heat transfer and fluid flow of natural convection in inclined cavity full of $\mathrm{Cu}$-water $\mathrm{Nano}$ fluid and partially heated. . The Prandtl number is kept constant at 7.02 corresponding to water. Aspect ratio and solid volume fraction are changed from 0.5 to 4 and from $0 \%$ to $4 \%$ respectively, and the inclination angel is varied from $0^{\circ}$ to 90 . They found that the efficiency of heat transfer is enhanced by the increment of nanoparticles ratio into base liquid; but there is an optimum solid volume fraction which promotes the heat transfer rate. Additionally they found that the diameter of solid particle is an imperative parameter that influences the heat transfer efficiency, its effect is more critical than the concentration itself.

\section{Mathematical Model and numerical analysis:}

The basic flow configuration, under study, is shown in Fig. 1. A three dimensional pipe have $1 \mathrm{~m}$ length and $25 \mathrm{~mm}$ inner diameter and $30 \mathrm{~mm}$ outer diameter contains circular fins with $30 \mathrm{~mm}$ inner diameter and $50 \mathrm{~mm}$ outer diameter and thickness of fins is $2 \mathrm{~mm}$ and The distance between each fin and the second fin is $48 \mathrm{~mm}$ was spotted in the simulation. The continuity, momentum and energy equations for a three dimensional incompressible laminar flow has been solved using appropriate boundary conditions by mean computational fluid dynamics technique. Following assumptions have been made: three-dimensional problem, there is no viscous dissipation, no gravity acts, the fluid properties are various according to volume concentration of Nano particles and radiation heat exchange was assumed negligible.

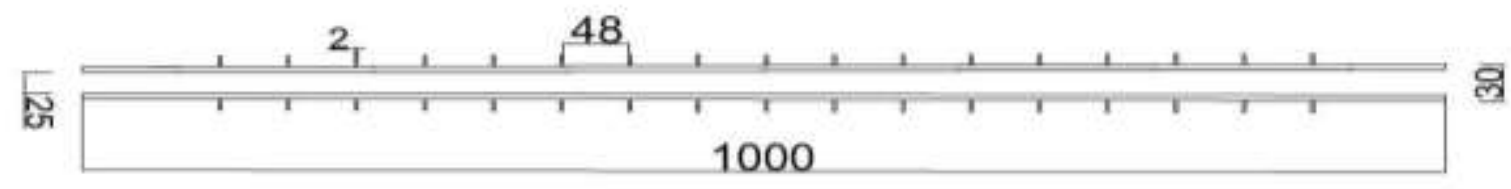

Figure (1): Schematic diagram of the physical system

The three-dimensional governing equations for the conservation of mass, momentum and energy and for the single phase are solved using a finite volume approach. The spatial discretization is achieved through a second-order upwind scheme. The SIMPLEC algorithm is selected to overcome the pressure-velocity coupling. All calculations are steady state and three-dimensional.

At steady state conditions using above assumption, the governing equations as given below [7]:

Continuity equation:

$$
\nabla \cdot\left(\rho_{\mathrm{nf}} \mathbf{V}\right)=0
$$

Momentum equation:

$$
\nabla \cdot\left(\rho_{\mathrm{nf}} \mathbf{V} \mathbf{V}\right)=-\nabla \mathrm{P}+\nabla \cdot\left(\mu_{\mathrm{nf}} \mathbf{V}\right)
$$

Energy equation:

$$
\nabla \cdot\left(\rho_{\mathrm{nf}} \mathrm{CVT}\right)=\nabla \cdot\left(\mathrm{k}_{\mathrm{nf}} \nabla \mathrm{T}\right)
$$

The effective physical properties of the nanofluids in the above equations are:

\section{1- Density:}

The density ( $\square n f$ ) in $\mathrm{kg} / \mathrm{m}^{3}$ is determined by the following equation: 


$$
\rho_{n f}=(1-\phi) \rho_{f}+\phi \rho_{s}
$$

\section{2-Dynamic viscosity:}

The viscosity ratio of the Nano fluid is calculated by the following equation:

$$
\mu_{n f}=\frac{\mu_{f}}{(1-\phi)^{2.5}}
$$

\section{3-Thermal Diffusivity}

The thermal diffusivity of the Nano fluid is determined by the following equation:

$$
\alpha_{n f}=\frac{k_{n f}}{\left(\rho C_{p}\right)_{n f}}
$$

\section{4-Heat Capacity}

The heat capacity of the Nano fluid is calculated by the following equation:

$$
\left(\rho C_{p}\right)_{n f}=(1-\phi)\left(\rho C_{p}\right)_{f}+\phi\left(\rho C_{p}\right)_{s}
$$

\section{5-Thermal conductivity}

The thermal Conductivity of Nano fluid is determined by the following equation:

Where:

F: Fluid

nf :Nanofluid

s: Solid of particle

Table (1): Thermo physical Properties of nano fluid .

\begin{tabular}{|c|c|c|}
\hline Property & $\begin{array}{c}\text { Fluid Phase } \\
\text { (Water) }\end{array}$ & Nanoparticle (AL2O3) \\
\hline$\rho \quad\left(\mathrm{kg} / \mathrm{m}^{3}\right)$ & 998.2 & 3880 \\
\hline $\mathrm{Cp}(\mathrm{J} / \mathrm{kg} \mathrm{K})$ & 4182 & 729 \\
\hline $\mathrm{k}(\mathrm{W} / \mathrm{m} \mathrm{K}$ & 0.6 & 42 \\
\hline$\mu(\mathrm{kg} / \mathrm{m} . \mathrm{s})$ & 0.001003 & - \\
\hline
\end{tabular}

Table (2) : Thermo physical Properties of nano fluid with different volume concentration

\begin{tabular}{|c|c|c|c|}
\hline $\begin{array}{c}\text { Nano fluid } \\
\text { Water } / \mathrm{AL} 2 \mathrm{O} 3)\end{array}$ & $\square \square \square$ & $\square \square \square$ & $\square=1$ \\
\hline$\rho\left(\mathrm{kg} / \mathrm{m}^{3}\right)$ & 1142.2 & 1084.6 & 1027 \\
\hline $\mathrm{Cp}(\mathrm{J} / \mathrm{kg} \mathrm{K})$ & 3595 & 3811 & 4051 \\
\hline $\mathrm{k}(\mathrm{W} / \mathrm{m} \mathrm{K}$ & 0.69 & 0.65 & 0.61 \\
\hline$\mu(\mathrm{kg} / \mathrm{m} . \mathrm{s})$ & 0.001140 & 0.001082 & 0.001028 \\
\hline
\end{tabular}


The boundary conditions are specified as follows:

- At the tube inlet: $\mathrm{u}(\mathrm{y})=0.12 \mathrm{~m} / \mathrm{s}$ and $\mathrm{T}=\mathrm{Ti}=350^{\circ} \mathrm{K}$

- At the tube outlet: pressure outlet boundary $\mathrm{P}=0$

- At the wall: convection heat transfer on the extended surface with heat transfer coefficient $=20$ to the environment, $\mathrm{T}=300 \mathrm{~K}$

\section{Result and discussion}

Through numerical analysis by ANSYS 14.5 on two types of tubes, one of which is smooth tube and the other is finned tube and two types of fluid one of which is pure water and the other is Nano fluid and for the purpose of comparing them, the results showed that The presence of nanoparticles with fluid at work occupies the interstellar distances between the working fluid molecules and will therefore increase the heat transfer as shown in table (3) and Fig.2 and Fig3 , compared to the results of fluid without fins and without nano, When the speed changes in a given concentration and a particular model exists, the heat transfer will increase as shown in Fig. 4 and Fig.5 and The results from the Temperature contours showed that the process of cooling through the finned tubes is better than the tube that does not contain fins as shown in Fig.6.

Table (3): The Results of the case study

\begin{tabular}{|c|c|c|c|c|c|c|c|}
\hline $\begin{array}{l}\text { Type } \\
\text { of tube }\end{array}$ & $\begin{array}{l}\text { Number } \\
\text { of node }\end{array}$ & $\begin{array}{l}\text { Number } \\
\text { of } \\
\text { element }\end{array}$ & \multicolumn{2}{|c|}{$\begin{array}{l}\text { Velocity } \\
\text { value } \mathrm{m} / \mathrm{s}\end{array}$} & $\begin{array}{l}\text { Type } \\
\text { of } \\
\text { fluid }\end{array}$ & $\begin{array}{l}\text { Volume } \\
\text { concentration }\end{array}$ & $\begin{array}{l}\text { Heat transfer } \\
\text { coefficient } \\
\mathrm{W} / \mathrm{m}^{2} \cdot \mathrm{k}\end{array}$ \\
\hline \multirow{8}{*}{$\begin{array}{l}\text { Smooth } \\
\text { tube }\end{array}$} & \multirow[t]{8}{*}{26029} & \multirow[t]{8}{*}{18957} & \multirow[t]{4}{*}{0.08} & \multicolumn{2}{|c|}{ Pure water } & $0 \%$ & 148 \\
\hline & & & & \multirow{3}{*}{\multicolumn{2}{|c|}{ Nano fluid }} & $1 \%$ & 151 \\
\hline & & & & & & $3 \%$ & 156 \\
\hline & & & & & & $5 \%$ & 161 \\
\hline & & & \multirow[t]{4}{*}{0.12} & \multicolumn{2}{|c|}{ Pure water } & $0 \%$ & 171 \\
\hline & & & & \multirow{3}{*}{\multicolumn{2}{|c|}{ Nano fluid }} & $1 \%$ & 173 \\
\hline & & & & & & $3 \%$ & 180 \\
\hline & & & & & & $5 \%$ & 186 \\
\hline \multirow{8}{*}{$\begin{array}{l}\text { Finned } \\
\text { tube }\end{array}$} & \multirow[t]{8}{*}{28592} & \multirow[t]{8}{*}{53714} & \multirow[t]{4}{*}{0.08} & \multicolumn{2}{|c|}{ Pure water } & $0 \%$ & 149 \\
\hline & & & & \multirow{3}{*}{\multicolumn{2}{|c|}{ Nano fluid }} & $1 \%$ & 151.5 \\
\hline & & & & & & $3 \%$ & 157 \\
\hline & & & & & & $5 \%$ & 162.5 \\
\hline & & & \multirow[t]{4}{*}{0.12} & \multicolumn{2}{|c|}{ Pure water } & $0 \%$ & 172 \\
\hline & & & & \multirow{3}{*}{\multicolumn{2}{|c|}{ Nano fluid }} & $1 \%$ & 174 \\
\hline & & & & & & $3 \%$ & 181 \\
\hline & & & & & & $5 \%$ & 187 \\
\hline
\end{tabular}




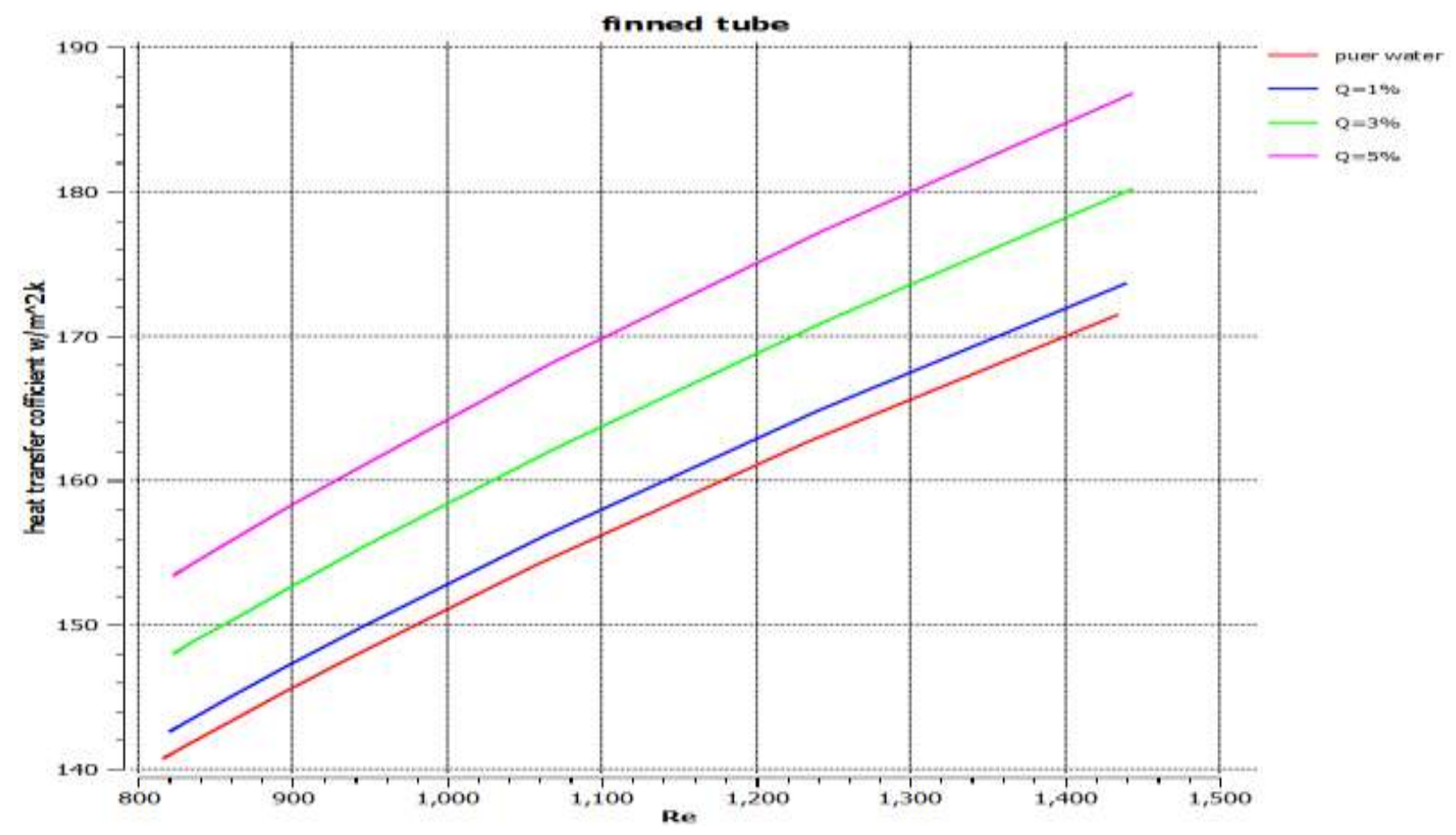

Figure (2): Heat Transfer coefficient Variation with Reynolds Number for the finned tube with volume concentration $(0 \%, 1 \%, 3 \%, 5 \%)$

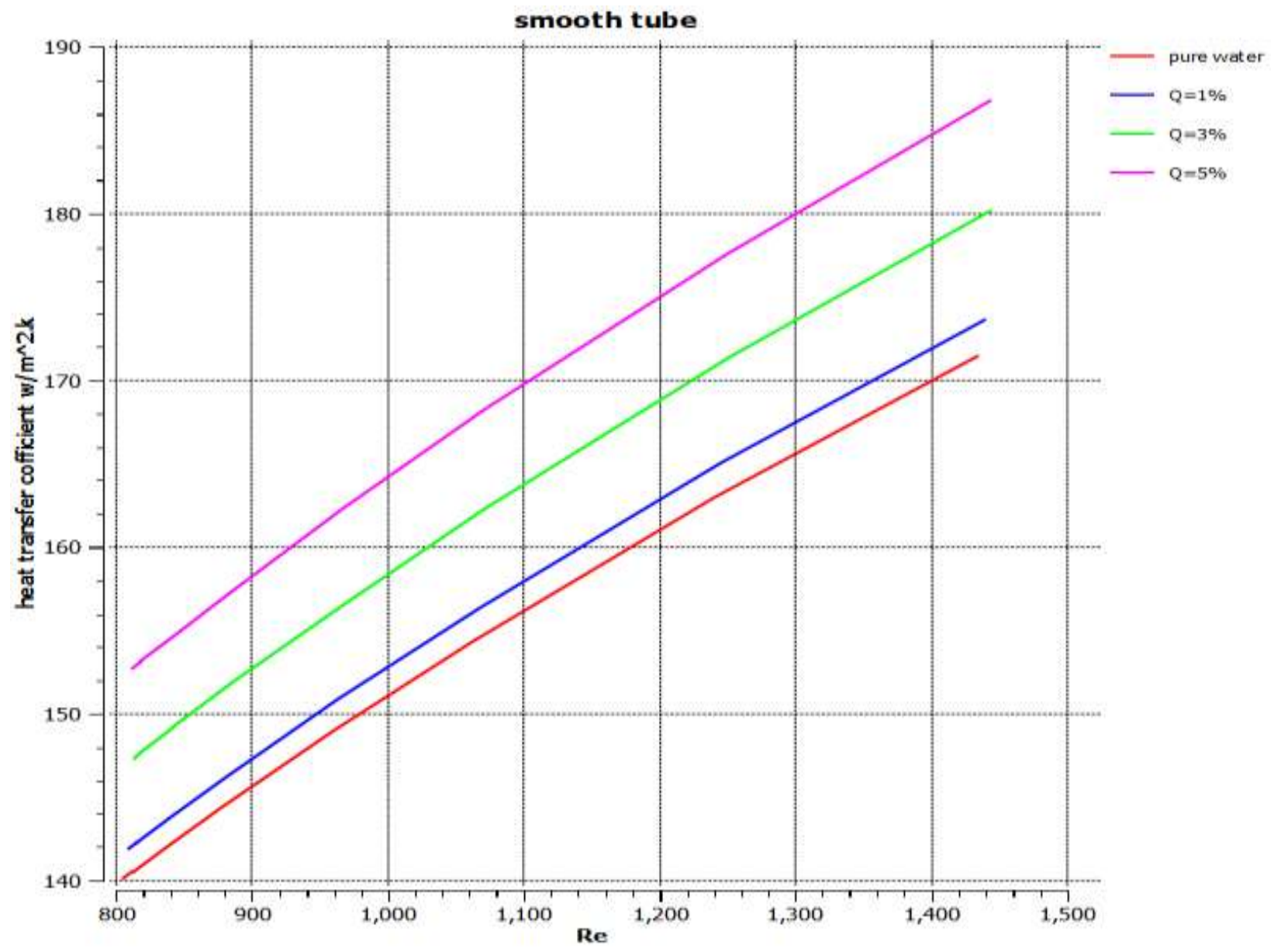

Figure (3): Heat Transfer coefficient Variation with Reynolds Number for the smooth tube with volume concentration $(0 \%, 1 \%, 3 \%, 5 \%)$ 


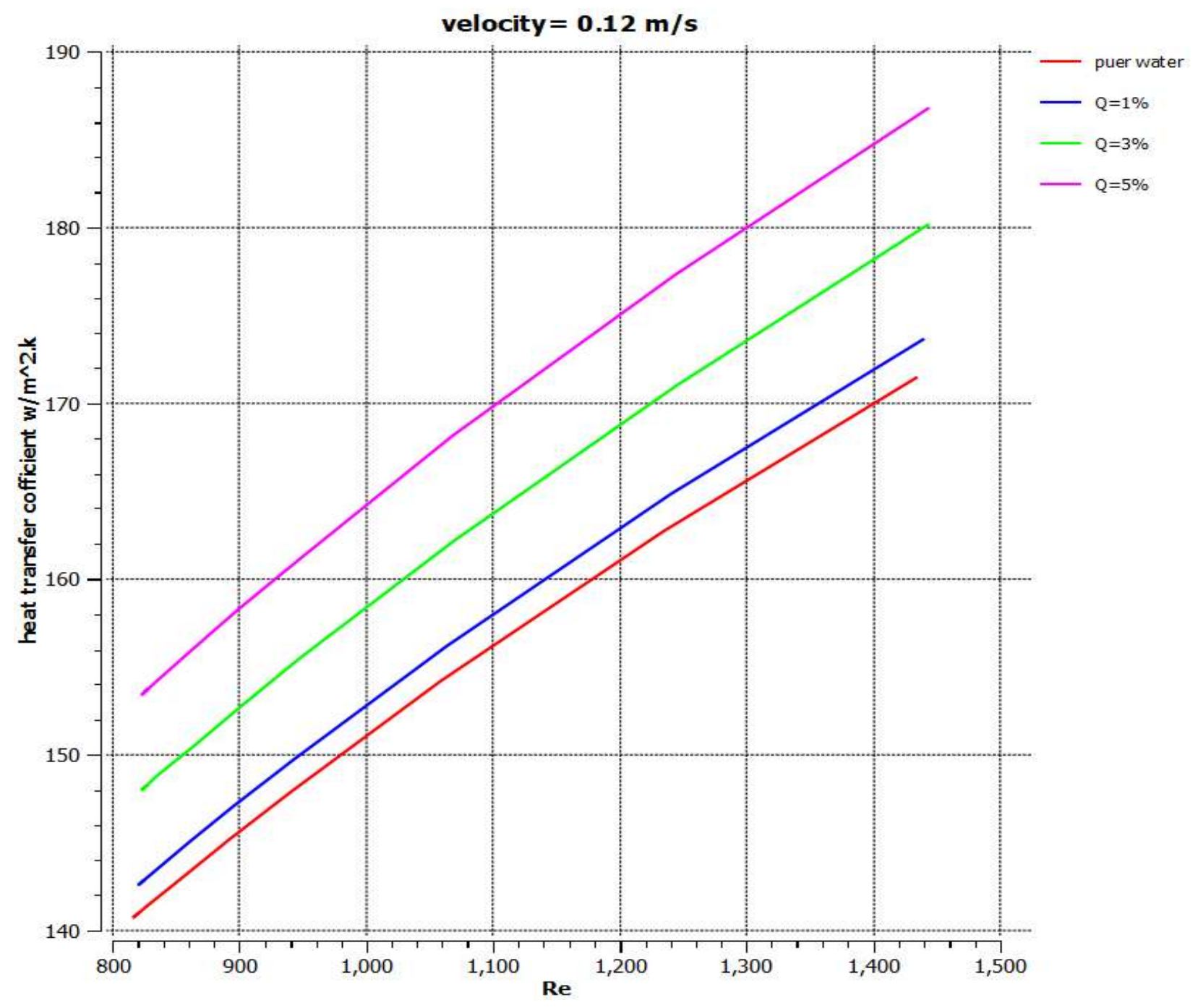

Figure (4): Heat Transfer coefficient Variation with Reynolds Number for the finned tube with velocity $=$ $0.12 \mathrm{~m} / \mathrm{s}$ and volume concentration $(0 \%, 1 \%, 3 \%, 5 \%)$ 


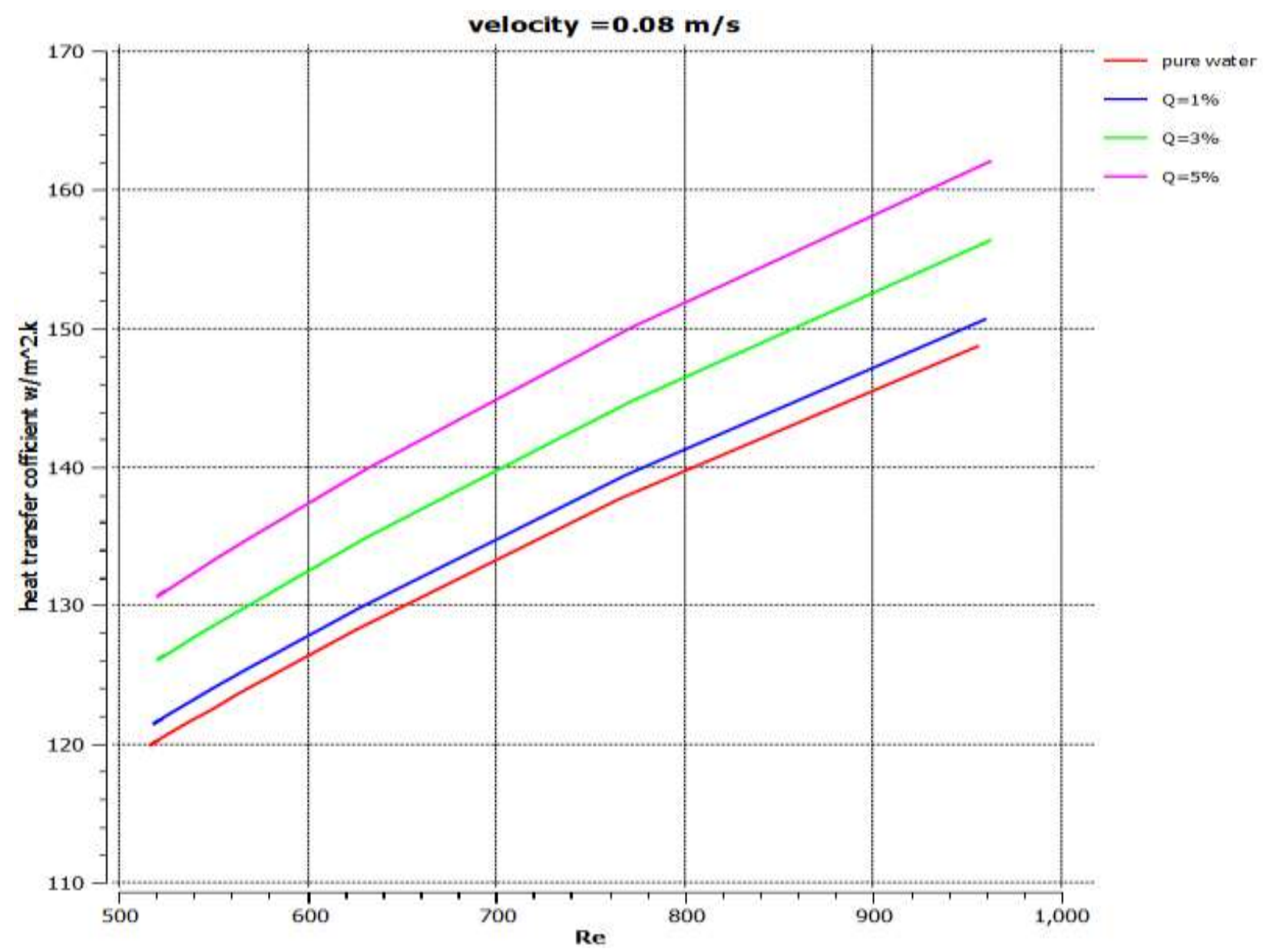

Figure (5): Heat Transfer coefficient Variation with Reynolds Number for the finned tube with velocity = $0.08 \mathrm{~m} / \mathrm{s}$ and volume concentration $(0 \%, 1 \%, 3 \%, 5 \%)$

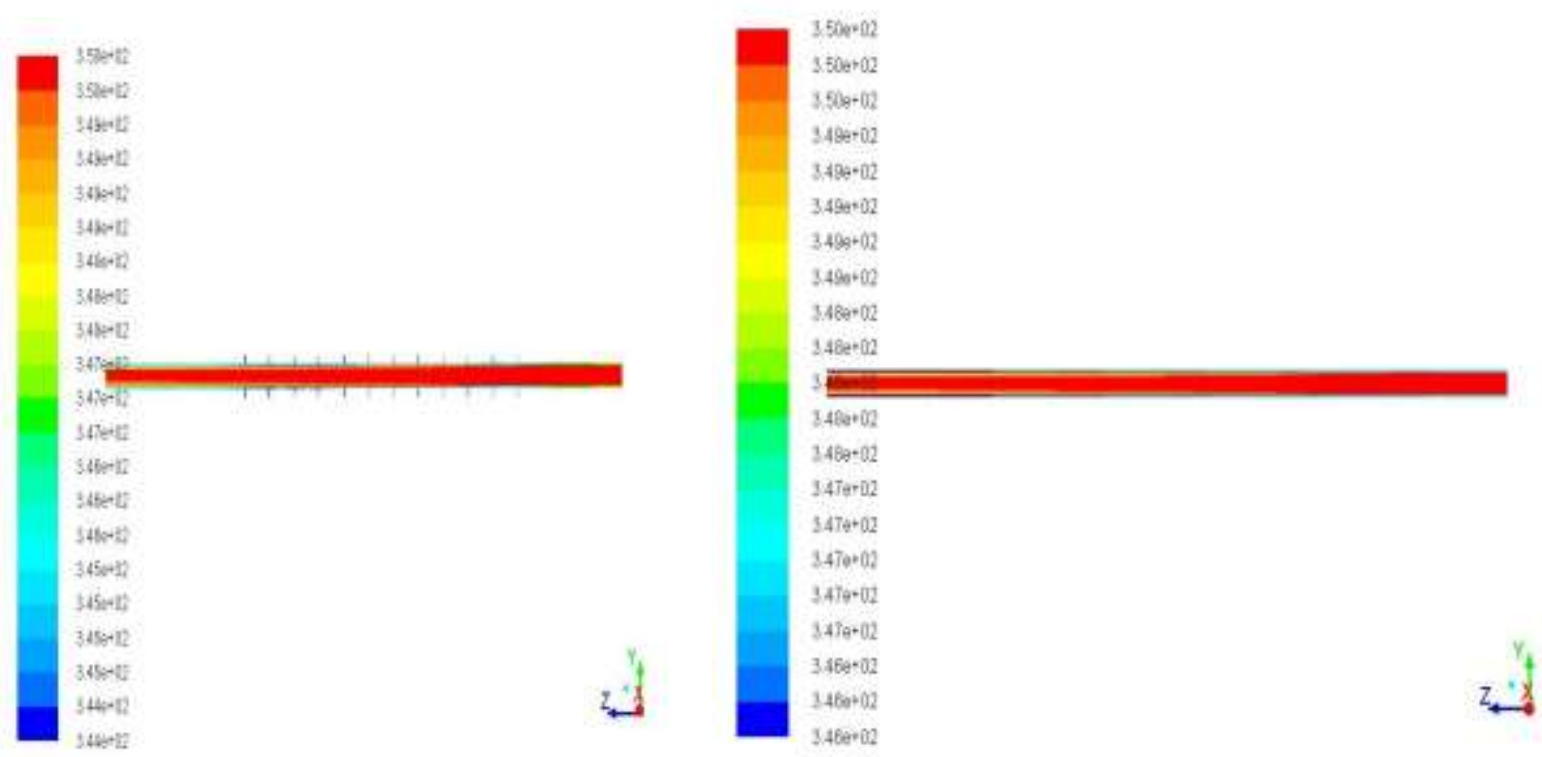

Figure (6): Temperature contours map for AL2O3-Water Nano-fluid $(\mathrm{Q}=5 \%)$ for finned and smooth tube. 


\section{Conclusions:}

As the results show, heat transfer through finned tube is better than heat transfer through tubes without fins, as well as the use of nano fluid is better than using pure water.

\section{References:}

[1] Amit Thakur\& Sushant Samir, 2016, Heat Transfer Enhancement in Circular Wavy Grooved Surface Tube Using Alumina-Water Nanofluid, PEC University of Technology, India

[2] Zamzamian A, Nasseri S, Oskouie, Doosthoseini A, Joneidi A, Pazouki M. Experimental investigation of forced convective heat transfer coefficient in nanofluids of A12O3/EG and $\mathrm{CuO} / \mathrm{EGin}$ a double pipe and plate heat exchangers under turbulent flow. Exp Ther Fluid Sci, Vol. 35, PP.495-502, 2011.

[3] Naik MT, Vojkani E, Ravi G. "Numerical investigation of turbulent flow and heat transfer characteristics of PGW-CuO nanofluids". Int J. M. M. Mech Eng, 2:141-5, 2013.

[4] Sheikholeslami, M.; Ellahi, R.; Hassan, M.; Soleimani, S. "A study of natural convection heat transfer in a nanofluid filled enclosure with elliptic inner cylinder". Int. J. Numer. Methods Heat Fluid Flow, Vol. 24, PP. 1906-1927, 2014.

[5] Hsien-Hung Ting and Shuhn-Shyurng Hou, "Investigation of Laminar Convective Heat Transfer for Al2O3-Water Nanofluids Flowing througha Square Cross-Section Duct with a Constant Heat Flux", J. Materials, Vol. 8, PP. 5321-5335, 2015.

[6] Bouhalleba, M. \& Abbassi, H. "Numerical investigation of heat transfer by $\mathrm{CuO}$-water Nano fluid in rectangular enclosures". Heat transfer Engineering, Vol. 37, Issue 1, PP. 13-23, 2016.

[7] Ho, C. J., Chen, M. W. and Li, Z. W., "Numerical simulation of natural convection of nanofluid in a square enclosure: Effects due to uncertainties of viscosity and thermal conductivity", Int. J. Heat Mass Transf., Vol. 51, PP. 4506-4516, 2008. 